Gut, 1972, 13, 894-899

\title{
The effect of retaining antral innervation on the reductions of gastric acid and pepsin secretion after vagotomy
}

\author{
R. J. CLARKE, R. N. Allan, AND J. ALEXANDER-Williams ${ }^{1}$ \\ From the General Hospital, Birmingham
}

SUMMARY The result of a prospective trial of 40 patients with duodenal ulcer treated either by proximal gastric vagotomy (antrum innervated) or by selective vagotomy (antrum denervated) shows that they are equally effective in reducing gastric acid and pepsin secretion.

Preservation of antral innervation by proximal gastric vagotomy reduces gastric secretion as effectively as denervation of the entire stomach.

Vagotomy combined with a drainage procedure is now established as the elective method of treatment for duodenal ulceration by the majority of surgeons in Britain. However, over the last 15 years it has become increasingly clear that a proportion of patients develop sequelae such as diarrhoea, 'dumping', or vomiting, which seem to be directly related to the operation (Goligher, Pulvertaft, Irvine, Johnston, Waiker, Hall, Willson-Pepper, and Matheson, 1972).

Amdrup and Jensen (1970) and Johnston and Wilkinson (1970) suggested that these sequelae could be minimized or abolished by performing a proximal gastric vagotomy without a drainage procedure (synonyms 'highly selective vagotomy', 'parietal cell vagotomy', 'selective proximal vagotomy'). Proximal gastric vagotomy denervates the acid-secreting area of the stomach but preserves the innervation to the gastric antrum. Burge, MacLean, Stedeford, Penn, and Hollanders (1969) suggested that a drainage procedure was not necessary with selective vagotomy in the absence of duodenal stenosis. A randomized trial of proximal gastric vagotomy and selective vagotomy was planned to see whether preservation of antral innervation was consistent with an adequate reduction of gastric secretion; the only difference between the two operations was the presence, or absence, of antral innervation.

The first 20 patients in the trial were treated by proximal gastric vagotomy or selective vagotomy ${ }^{1}$ Requests for reprints to J.A.W.

Received for publication 19 September 1972. without a drainage procedure, but, because of gastric stasis in patients with a selective vagotomy (Clarke, McFarland, and Williams, 1972), a pyloroplasty was included in all operations on the second 20 patients in the trial. The pyloroplasty was performed with both types of vagotomy so that once again the only difference between the two groups was the presence or absence of antral innervation.

\section{Material}

Forty consecutive male patients with uncomplicated duodenal ulcers were included in the trial; no patient was excluded due to obesity.

All patients had unequivocal evidence of a duodenal ulcer on barium meal examination and at operation. All operations were performed by one surgeon (R.J.C.). At operation coexistent biliary or other gastrointestinal pathology was excluded and a proximal gastric vagotomy was performed.

\section{Technique of Operation}

The technique of proximal gastric vagotomy was similar to that described by Amdrup and Jensen (1970). The anterior and posterior nerves of Latarjet (Latarjet, Cluzet, and Wertheimer, 1921) pass along the lesser curve of the stomach with the left gastric vessels to provide the vagal innervation to the antrum. The dissection was started in the region of the incisura dividing branches of the nerves of Latarjet and the left gastric vessels which run to the body of the stomach, keeping close to the wall of 
the stomach to avoid damage to the nerves. The lesser sac was entered and the left gastric bundle containing the two nerves of Latarjet was separated from the stomach by dissecting proximally to just below the cardia. The serosa overlying the cardia was then dissected obliquely across the cardia to the cardiooesophageal angle, keeping as distal as possible to avoid damage to the anterior nerve of Latarjet as it passes obliquely across the cardia from the main anterior vagal trunk on the oesophagus. The small anterior vagal branches passing to the gastric fundus were carefully divided. By freeing the oesophagus and cardia posteriorly, the small posterior vagal branches passing down on the oesophagus were also divided to complete the proximal gastric vagotomy.

All patients in the trial had a $4 \mathrm{~cm}$ longitudinal gastrotomy in the body of the stomach immediately proximal to the antrum and duodenal stenosis was excluded by passing the index finger through the pylorus into the second part of the duodenum. Through the gastrotomy the antral-parietal mucosal boundary was easily delineated using Congo Red dye after pentagastrin stimulation (Amdrup and Jensen, 1970). The gastrotomy was then closed.

The choice of vagotomy was randomly selected by computer. The surgeon was informed of the choice of vagotomy only at this stage in the operation. If a proximal gastric vagotomy was selected, the operation was concluded by checking that the vagal nerve supply to the antrum was intact. The modified electrodes from a Burge vagotomy stimulator were applied to the main vagal trunks at the hiatus resulting in marked antral contractions and peristalsis (atropine abolished this response and is avoided in pre-medication). If a selective vagotomy was selected the left gastric bundle, including the nerves of Latarjet, was divided close to the antrum.

The last 20 patients in the trial had a Weinberg (1964) pyloroplasty.

\section{Gastric Secretion Tests}

Gastric secretion was assessed before operation and between three and four months after operation in all patients. The patient fasted for 12 hours before the test. A nasogastric double-lumen Salem sump tube was passed and an insulin/pentagastrin test (modified Baron, Gutierrez, Spencer, Tinker, and Welbourn, 1969; Baron, Cowley, Gutierrez, Spencer, Tinker, and Welbourn, 1970) carried out.

The basal secretion of gastric juice was aspirated by continuous suction for half an hour. The patient was then given an intravenous injection of 0.25 units of insulin per $\mathrm{kg}$ body weight and the gastric secretion collected in 15-minute samples for a further two hours. This was followed by an intramuscular injection of $6 \mu \mathrm{g}$ of pentagastrin per $\mathrm{kg}$ body weight and the gastric secretion was collected for a further hour.

The concentration of hydrochloric acid in each 15-minute aliquot of gastric juice was measured by titration with $\mathrm{N} / 10$ sodium hydroxide to $p \mathrm{H} \mathrm{7.0}$ using a Radiometer autotitrator. The pepsin content of the gastric juice was measured, in the last 20 patients in the trial, by the method of Anson (1938).

The acid outputs are expressed as m-equiv $\mathrm{HCl}$ per hour. The basal acid output (BAO) is obtained by multiplying the half-hour basal output by 2 . The maximum acid output after insulin stimulation [MAO(I)] is the sum of the greatest four consecutive quarter-hour samples. The peak acid output after pentagastrin stimulation $[\mathrm{PAO}(\mathrm{Pg})]$ is twice the sum of the greatest two consecutive quarter-hour samples. The hourly outputs of pepsin are calculated in an identical manner to the acid outputs so there is a basal pepsin output (BPO), a maximum pepsin output after insulin [MPO(I)] and a peak pepsin output after pentagastrin [PPO $(\mathrm{Pg})]$.

\section{Results}

\section{ACID SECRETION}

There is no difference in the preoperative or in the postoperative acid secretion between the patients with and without a pyloroplasty. For example, following proximal gastric vagotomy the MAO(I) was reduced by $98 \%$ and the PAO $(\mathrm{Pg})$ by $69 \%$ in the 10 patients without a pyloroplasty and the MAO(I) was reduced by $94 \%$ and the PAO $(\mathrm{Pg})$ by $74 \%$ in the 10 patients with a pyloroplasty. The gastric acid secretion of the 20 patients with a proximal gastric vagotomy will therefore be compared with the gastric secretion of the 20 patients with a selective vagotomy.

The average preoperative hourly acid outputs for the two groups of patients are shown in Table I.

\begin{tabular}{lccl}
\hline & $\begin{array}{l}\text { Proximal Gastric } \\
\text { Vagotomy }\end{array}$ & $\begin{array}{l}\text { Selective } \\
\text { Vagotomy }\end{array}$ & $\begin{array}{l}\text { Statistical } \\
\text { Difference }\end{array}$ \\
\hline Basal & $3.52 \pm 0.63$ & $5.59 \pm 1 \cdot 10$ & P $>0.05$ \\
MAO(I) & $27.48 \pm 2.63$ & $29.46 \pm 2.45$ & P $>0.25$ \\
PAO(Pg) & $43.54 \pm 3.30$ & $40.25 \pm 2.56$ & P $>0.20$ \\
\hline
\end{tabular}

Table I Average preoperative gastric acid secretion in 40 patients ${ }^{1}$

${ }^{1}$ Results in m-equiv $\mathrm{HCl} /$ hour $\pm \mathrm{SEM}$

There is no significant difference preoperatively in the MAO(I) or the PAO(Pg) between the two groups, but the difference in the BAO between the two groups is marginally significant ( $P$ just $<0.05$ ). 


\begin{tabular}{llll}
\hline & $\begin{array}{l}\text { Proximal Gastric } \\
\text { Vagotomy }\end{array}$ & $\begin{array}{l}\text { Selective } \\
\text { Vagotomy }\end{array}$ & $\begin{array}{l}\text { Statistical } \\
\text { Difference }\end{array}$ \\
\hline Basal & $0.819 \pm 0.312$ & $1.139 \pm 0.516$ & $\mathrm{P}>0.4$ \\
MAO(I) & $1.192 \pm 0.516$ & $2.23 \pm 0.454$ & $\mathrm{P}>0.1$ \\
PAO(Pg) & $12.58 \pm 1.70$ & $15.68 \pm 1.58$ & $\mathrm{P}>0.1$ \\
\hline
\end{tabular}

Table II Average postoperative gastric acid secretion in 40 patients 1

${ }^{1}$ Results in m-equiv $\mathrm{HCl} /$ hour $\pm \mathrm{SEM}$

The average postoperative hourly acid outputs for the two groups of patients are shown in Table II. There is no statistical difference in BAO, MAO(I), or $\mathrm{PAO}(\mathrm{Pg})$ between the two groups of patients.

There is a highly significant $(P<0.001)$ fall in all measurements of acid secretion following both operations. The mean reduction of BAO is $74 \%$ after selective proximal vagotomy and $80 \%$ after selective vagotomy. The mean reduction of MAO(I) is $96 \%$ after selective proximal vagotomy and $92 \%$ after selective vagotomy. The mean reduction of $\mathrm{PAO}(\mathrm{Pg})$ is $71 \%$ after selective proximal vagotomy and $61 \%$ after selective vagotomy.

The similarity of the acid secretion between the two groups both before and after operation is shown in Figure 1 where the average quarter-hour acid outputs ( \pm standard error or mean) during the insulin/pentagastrin tests are plotted. This illustrates that preservation of antral innervation by proximal gastric vagotomy results in a satisfactory reduction of acid secretion.

PEPSIN SECRETION

The average preoperative hourly pepsin outputs for the two groups of patients are shown in Table III. There is no statistical difference in the BPO, MPO(I), or $\mathrm{PPO}(\mathrm{Pg})$ between the two groups of patients.

The gastric secretion of pepsin during the insulin/

\begin{tabular}{lccl}
\hline & $\begin{array}{l}\text { Proximal Gastric } \\
\text { Vagotomy }\end{array}$ & $\begin{array}{l}\text { Selective } \\
\text { Vagotomy }\end{array}$ & $\begin{array}{l}\text { Statistical } \\
\text { Difference }\end{array}$ \\
\hline Basal & $38 \cdot 2 \pm 7 \cdot 5$ & $40 \cdot 2 \pm 8 \cdot 4$ & P $>0.8$ \\
MPO(I) & $242 \cdot 1 \pm 33 \cdot 5$ & $216.7 \pm 29 \cdot 8$ & P $>0.5$ \\
PPO(Pg) & $196 \cdot 6 \pm 29.4$ & $173.5 \pm 27 \cdot 8$ & P $>0.5$ \\
\hline
\end{tabular}

Table III Average preoperative gastric pepsin secretion in 20 patients ${ }^{1}$

${ }^{1}$ Results in mg per hour \pm SEM

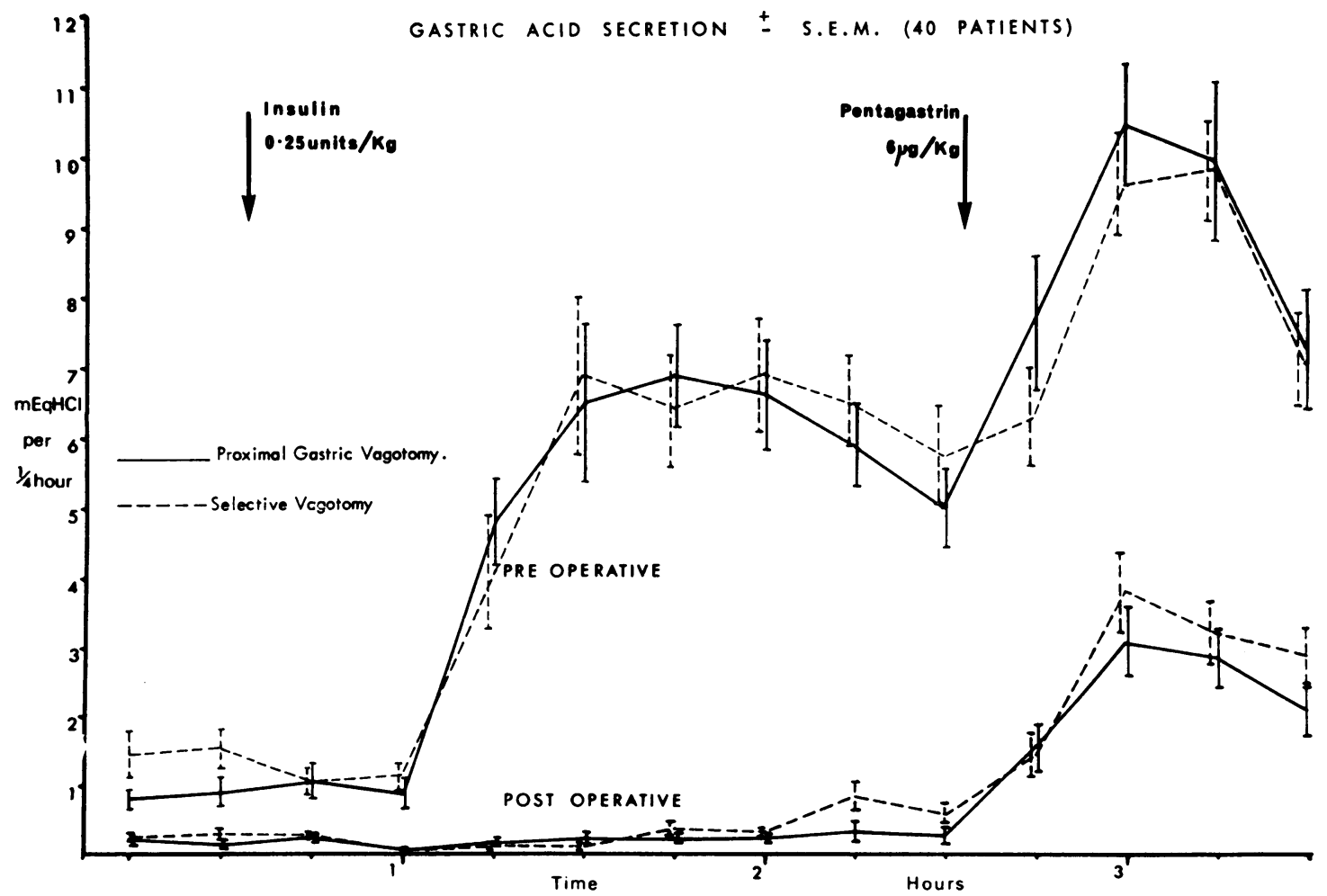

Fig. 1 Gastric acid secretion \pm standard error on mean (40 patients). 


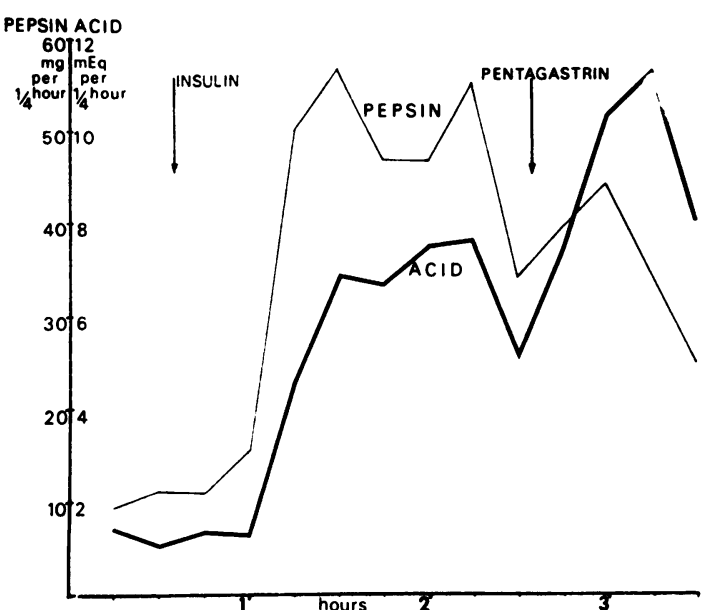

Fig. 2 Preoperative gastric acid and pepsin secretion with insulin and pentagastrin (20 patients).

pentagastrin test differs in certain respects from the acid secretion. Insulin is a stronger stimulus of pepsin secretion than is pentagastrin, which is illustrated in Fig. 2 where the average preoperative gastric acid and pepsin outputs per quarter-hour aliquot are plotted for the last 20 patients in the trial.

The average postoperative hourly pepsin outputs for the two groups of patients are shown in Table IV. Although the postoperative BPO, MPO(I), and $\mathrm{PPO}(\mathrm{Pg})$ are greater after selective vagotomy than after proximal gastric vagotomy, there is no statistical difference in the hourly pepsin outputs or in the percentage reductions in the hourly pepsin outputs between the two groups.

After vagotomy there is a highly significant $(P<0.001)$ fall in pepsin secretion which parallels the acid reductions in the individual patients. The mean reduction of $\mathrm{BPO}$ is $75 \%$ after selective proximal vagotomy and $50 \%$ after selective vagotomy. The mean reduction of MPO(I) is $94 \%$ after selective proximal vagotomy and $87 \%$ after

\begin{tabular}{lcll}
\hline & $\begin{array}{l}\text { Proximal Gastric } \\
\text { Vagotomy }\end{array}$ & $\begin{array}{l}\text { Selective } \\
\text { Vagotomy }\end{array}$ & $\begin{array}{l}\text { Statistical } \\
\text { Difference }\end{array}$ \\
\hline Basal & $9 \cdot 50 \pm 4.93$ & $20 \cdot 12 \pm 5 \cdot 72$ & P $>0 \cdot 1$ \\
MPO(I) & $15.48 \pm 6 \cdot 15$ & $29 \cdot 11 \pm 7.57$ & P $>0.1$ \\
PPO(Pg) & $61.40 \pm 12.22$ & $77.58 \pm 12.02$ & P $>0.3$ \\
\hline
\end{tabular}

Table IV Average postoperative gastric pepsin secretion in 20 patients ${ }^{1}$

${ }^{1}$ Results in mg per hour \pm SEM

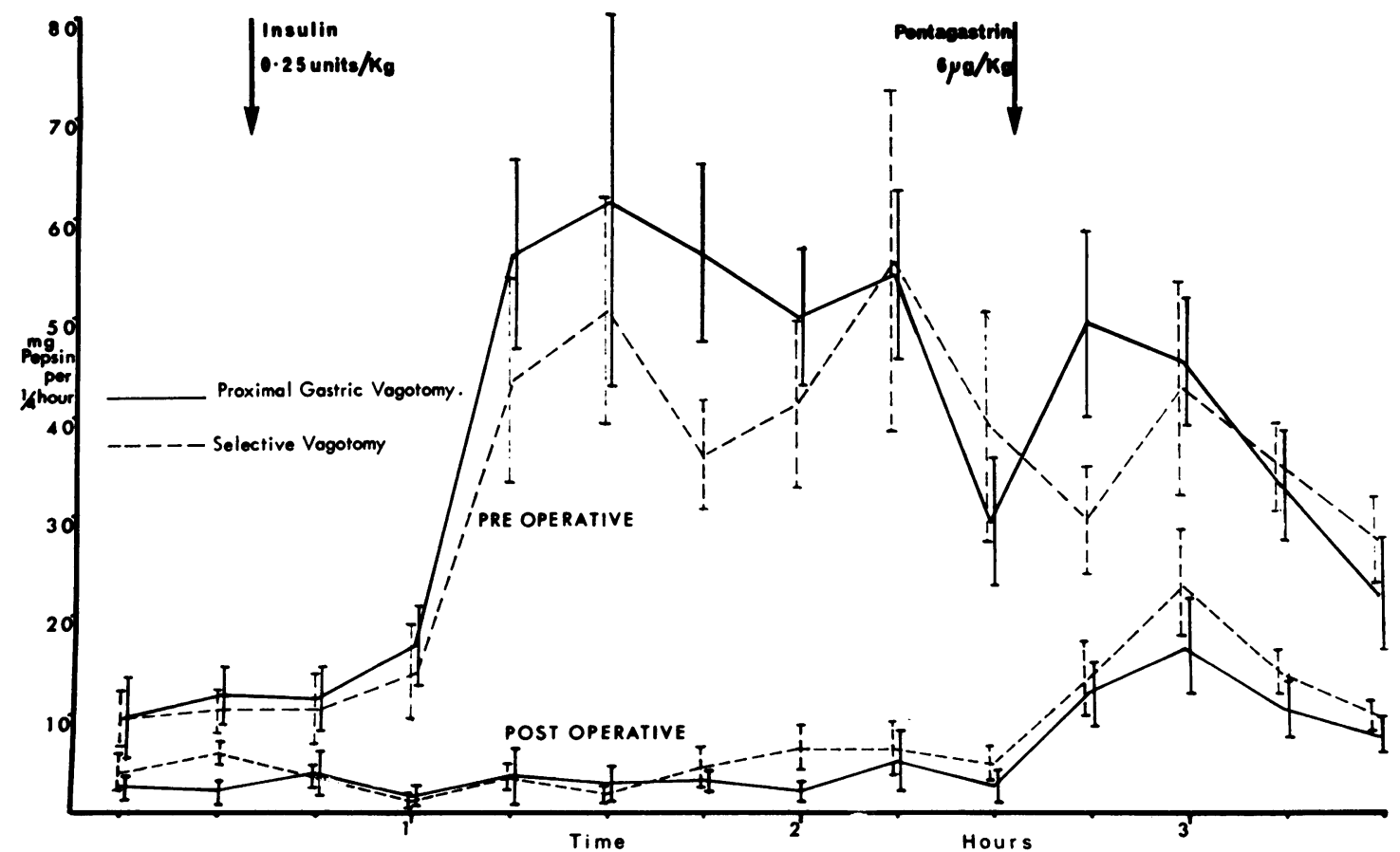

Fig. 3 Gastric pepsin secretion \pm standard error or mean (20 patients). 
selective vagotomy. The mean reduction of $\mathrm{PPO}(\mathrm{Pg})$ is $69 \%$ after selective proximal vagotomy and $56 \%$ after selective vagotomy. The similarity of the pepsin secretion between the two groups before and after operation is illustrated in Fig. 3 where the average quarter hour pepsin outputs $( \pm$ standard error of mean) during the insulin/pentagastrin tests are plotted. This illustrates that preservation of antral innervation by proximal gastric vagotomy results in a satisfactory reduction of pepsin secretion.

\section{ASSESSMENT OF INCOMPLETE VAGOTOMY}

The results of the individual postoperative acid secretion studies during insulin stimulation were studied to select those patients with evidence of residual vagal innervation to the acid-secreting area (positive insulin test). The criteria of Hollander (1948) were used for this assessment. An 'early' positive insulin test is a rise in acid secretion occurring in the first hour of insulin stimulation (Ross and Kay, 1964) and a 'late' positive insulin test is a rise in acid secretion occurring in the second hour of insulin stimulation.

Seven patients showed evidence of an incomplete vagotomy (Table V). The two patients with an 'early'

\begin{tabular}{|c|c|c|c|c|c|c|c|}
\hline \multirow[t]{2}{*}{ Criteria } & \multicolumn{7}{|c|}{ Operation } \\
\hline & $S V$ & $S V$ & $s V$ & $S P V$ & $S P V$ & $S V$ & $S V$ \\
\hline $\begin{array}{l}\text { Percentage reduction } \\
\text { in } \mathrm{PAO}(\mathbf{P g}) \\
\text { Postoperative }\end{array}$ & 21 & 19 & 71 & 65 & 44 & 37 & 50 \\
\hline $\begin{array}{l}\text { PAO(Pg) } \\
\text { 'Early' positive } \\
\text { response (Ross and } \\
\text { Kay, 1964) }\end{array}$ & 15.4 & $26 \cdot 7$ & $12 \cdot 8$ & $20 \cdot 9$ & $27 \cdot 3$ & $23 \cdot 68$ & 25.4 \\
\hline
\end{tabular}

Table V Patients with positive criteria of incomplete vagotomy (Hollander, 1948)

positive insulin test both had a proximal gastric vagotomy, and, although in one the $\mathrm{PAO}(\mathrm{Pg})$ was only reduced by the operation by $44 \%$ (from 48 to 27 m-equiv $\mathrm{HCl}$ per hour), in the second patient the $\mathrm{PAO}(\mathrm{Pg})$ was reduced by $65 \%$ by the operation (from 60 to 21 m-equiv $\mathrm{HCl}$ per hour). The five patients with a 'late' positive insulin test all had a selective vagotomy.

\section{Discussion}

We have found proximal gastric vagotomy to be a feasible method of treatment for any patient with duodenal ulceration, although a pyloroplasty must be added if duodenal stenosis is present and we do not advocate it if a coexistent gastric ulcer is present. It has not yet been necessary to abandon a proximal gastric vagotomy in any patient because of obesity or other technical factors.

The acid and pepsin secretion studies show that proximal gastric vagotomy and selective vagotomy result in similar reductions in gastric secretion. Johnston and Wilkinson (1970) and Amdrup and Jensen (1970) found similar reductions in PAO $(\mathrm{Pg})$ in this series after proximal gastric vagotomy. Bank, Marks, and Louw (1967) and Mason, Giles, Graham, Clark, and Goligher (1968) found similar reductions in maximal acid output with histamine stimulation after both selective and total vagotomy. Therefore, there is no evidence that preservation of the vagal innervation to the gastric antrum, by proximal gastric vagotomy, prevents adequate gastric acid reduction three to four months after operation.

Is the reduction in gastric secretion after proximal gastric vagotomy likely to be permanent? Amdrup, Kragelund, Humphrey, Smith, Goligher, and Johnston (1971) showed that although most patients after proximal gastric vagotomy had a negative insulin test by the criteria of Hollander (1948) immediately after vagotomy, over half the patients had a positive response when tested again more than one year after operation. However, this also occurs after both truncal and selective vagotomy (Gillespie, Elder, Gillespie, Kay, and Campbell, 1970; Watkin and Duthie, 1971). Long-term follow up of a large number of patients is required to determine whether the reduction of gastric secretion after proximal gastric vagotomy remains sufficient to prevent recurrent ulceration. Only then will the role of proximal gastric vagotomy in duodenal ulceration be established.

This work was supported by a grant from the Medical Research Council and the United Birmingham Hospitals Medical Endowment Research Fund.

\section{References}

Amdrup, E., and Jensen, H. E. (1970). Selective vagotomy of the parietal cell mass preserving innervation of the undrained antrum: a preliminary report of results in patients with duodenal ulcer. Gastroenterology, 59, 522-527.

Amdrup, E., Kragelund, E., Humphrey, C. S., Smith, R. B., Goligher, J. C., and Johnston, D. (1971). Evidence for partial vagal reinnervation of the stomach after highly selective vagotomy without a drainage procedure (H.S.V.) for duodenal ulcer in man. Gut, 12, 866.

Anson, M. (1938). The estimation of pepsin, trypsin, papain and cathepsin with haemoglobin. J. gen. Physiol., 22, 79-89.

Bank, S., Marks, I. N., and Louw, J. H. (1967). Histamine and insulin stimulated gastric acid secretion after selective and truncal vagotomy. Gut, 8, 36-41.

Baron, J. H., Cowley, D. J., Gutierrez, L. V., Spencer, J., Tinker, J., and Welbourn, R. B. (1970). Insulin and pentagastrin stimulated acid output in the unoperated subject. (Abstr.) 4th World Congress of Gastroenterology, Copenhagen, p. 201. 
Baron, J. H., Gutierrez, L. V., Spencer, J., Tinker, J., and Welbourn, R. B. (1969). The insulin test in the unoperated subject. Gut, 10, 1046-1047.

Burge, H., Maclean, C., Stedeford, R., Pinn, G., and Hollanders, D. (1969). Selective vagotomy without drainiage: an interim report. Brit. med. J., 3, 690-693.

Clarke, R. J., McFarland, J. B., and Williams, J. A. (1972). Gastric stasis and gastric ulcer after selective vagotomy without a drainage procedure. Brit. med. J., 1, 538-539.

Gillespie, G., Elder, J. B., Gillespie, I. E., Kay, A. W. and Campbell, E. H. G. (1970). The long term stability of the insulin test. Gastroenterology, 58, 625-632.

Goligher, J. C., Pulvertaft, C. N., Irvin, T. T., Johnston, D., Walker, B., Hall, R. A., Willson-Pepper, J., and Matheson, T. S. (1972). Five to eight year results of truncal vagotomy and pyloroplasty for duodenal ulcer. Brit. med. J., 1, 7-13.

Hollander, F. 1948). Laboratory procedures in the study of vagotomy with particular reference to the insulin test. Gastroenterology, 11, 419-425.

Johnston, D., Thomas, D. G., Checketts, R. G., and Duthie, H. L.
(1967). An assessment of postoperative testing for completeness of vagotomy. Brit. J. Surg., 54, 831-833.

Johnston, D., and Wilkinson, A. R. (1970). Highly selective vagotomy without a drainage procedure in the treatment of duodenal ulcer. Brit. J. Surg., 57, 289-296.

Kay, A. W. (1967). Memorial lecture: an evaluation of gastric acid secretion tests. Gastroenterology, 53, 834-844.

Latarjet, Cluzet, and Wertheimer (1921). Effects de la section et de l'excitation des nerfs propres de l'estomac sur la motricite de cet organe. C. R. Soc. Biol. (Paris), 84, 985-987.

Mason, M.C., Giles, G. R., Graham, N. G., Clark, C. G., and Goligher, J. C. (1968). An early assessment of selective and total vagotomy. Brit. J. Surg., 55, 677-680.

Ross, B., and Kay, A. W. (1964). The insulin test after vagotomy. Gastroenterology, 46, 379-386.

Watkin, D. F. L., and Duthie, H. L. (1971). Changes in the postoperative insulin test in relation to recurrent duodenal ulceration. Gut, 12, 303-310.

Weinberg, J. A. (1964). Pyloroplasty and vagotomy for duodenal ulcer. Curr. Probl. Surg. 